Original paper

\title{
Fixed-time and continuous assays of very-low-density lipoprotein secretion rate from rat liver: mean vs. instantaneous velocity
}

\author{
Kousar Daneshnia, Mehdi Rasouli \\ Department of Clinical Biochemistry and Immunogenetic Research Center, Faculty of Medicine, Mazandaran University of Medical Sciences, \\ Sari, Mazandaran, Iran
}

\begin{abstract}
Aim of the study: The secretion rate of triglyceride from rat liver is assayed by the measurement of triglyceride accumulation in plasma when its clearance is inhibited. The aim of the study was to measure and compare the secretion rate of triglyceride from rat liver by two methods of fixed-time and continuous assays.

Material and methods: A single dose of $200 \mathrm{mg}$ of poloxamer-407 (P-407) was injected i.p. into starved male rats. The secretion rate of triglyceride was measured by fixed-time and continuous assays.

Results: The time course for the changes of serum triglyceride following injection of P-407 showed three distinct phases: a lag period of about 30 minutes, a linear increase in serum triglyceride that lasted more than 4 hours, and a slight decline of triglyceride accumulation that lasted about 24 hours. The mean rate of triglyceride secretion was $234.1 \pm 9.6 \mathrm{mg} / \mathrm{dl} / \mathrm{h}$ during the linear phase. The linear phase was divided into five time protocols of $240,180,120,60$, and 30 minutes and the secretion rate was measured at three points of time in each protocol. The mean rate of triglyceride secretion was $3.91 \pm 0.15,3.83 \pm 0.16,3.76 \pm 0.29,3.57 \pm 0.43$ and $3.13 \pm 0.34 \mathrm{mg} / \mathrm{d} / \mathrm{min}$ in these protocols respectively. In the kinetic assay, the change in the absorbance per three successive five minutes $(\Delta \mathrm{A} / \Delta \mathrm{t})$ was measured and the secretion rate was calculated as $3.82 \pm 0.11 \mathrm{mg} / \mathrm{d} / \mathrm{min}$.

Conclusions: The rate of triglyceride secretion can be measured by both fixed-time and kinetic assays and was about $3.82 \pm 0.11 \mathrm{mg} / \mathrm{dl} / \mathrm{min}$. The results of the two methods are more corresponded as the mean and instantaneous velocity respectively.
\end{abstract}

Key words: liver, triglyceride, poloxamer, secretion rate, VLDL.

\section{Address for correspondence:}

Prof. Mehdi Rasouli, Department of Clinical Biochemistry and Immunogenetic Research Center, Faculty of Medicine, Mazandaran University of Medical Sciences, Sari, Mazandaran, Iran, phone: +98-912-3489560, fax: +98-151-3247106, e-mail: mehdi.rasouli@yahoo.com

\section{Introduction}

The liver is the major source of plasma triglyceride in the fasted state [1]. Triglyceride is hydrolyzed to glycerol and fatty acids by lipoprotein lipase (LPL) located on the endothelium of capillaries [2]. In any interval of time, the mass of triglyceride secreted from the liver $\left(\mathrm{m}_{\mathrm{s}}\right)$ is equal to the mass that is hydrolyzed and cleared from the plasma $\left(\mathrm{m}_{\mathrm{c}}\right)$ plus the mass variation of triglyceride in plasma $\left(\mathrm{m}_{\mathrm{p}}\right)$ [3]:

$$
m_{s}=m_{c}+m_{p}
$$

By differentiation of the mass relative to the time as $\mathrm{dm} / \mathrm{dt}$, the terms will be changed to rates as follows:

$$
\begin{gathered}
\mathrm{dm} / \mathrm{st}=d m_{c} / d t+d m_{p} / d t \\
V_{s}=V_{c}+V_{p}
\end{gathered}
$$

This means that the level of triglyceride in plasma is balanced by the rate of the secretion from the liver $\left(\mathrm{V}_{\mathrm{s}}\right)$ and clearance from the plasma $\left(\mathrm{V}_{\mathrm{c}}\right)$ :

$$
V_{p}=V_{s}-V_{c}
$$

$\mathrm{V}_{\mathrm{p}}$ stands for the changes of plasma triglyceride in a particular time interval (i.e. one hour or minute). 
LPL is the rate limiting step in the clearance of triglyceride from the blood stream [2]. Tyloxapol (Triton-1339) and poloxamer (P-407) are nonionic detergents that inhibit LPL completely after a single injection at least

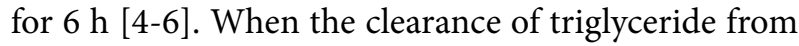
the plasma is inhibited completely, the term of $\mathrm{V}_{c}$ is equal to zero and the rate of triglyceride secretion will be as it accumulates in plasma:

$$
V_{c}=0, \quad V_{p}=V_{s}
$$

This method is applied to estimate the very-low-density lipoprotein (VLDL) associated triglyceride secretion rate from the liver [5-9] and to induce artificial hyperlipidemia [10-12]. The model of experimental lipemia is used to study the effects and mechanism of hypolipidemic drugs [10-12].

There are two protocols to measure the enzyme activity in plasma: fixed-time and continuous monitoring methods [13]. In a typical fixed-time reaction, the enzyme activity is measured by adding $100 \mu \mathrm{l}$ of serum to $3 \mathrm{ml}$ of reagent and incubated for a fixed time period, usually 30 minutes. In the kinetic assay, after one minute lag time, the progress of the reaction is usually monitored continuously during the initial three minutes [13]. We developed this idea for the measurement of the secretion rate of triglyceride from the liver. In the classical fixed-time method, the mean secretion rate of triglyceride from rat liver is usually assayed for two, three or four hours [4-9]. The average triglyceride secretion rate from rat liver is about $250 \mathrm{mg} / \mathrm{dl} / \mathrm{h}$ (or $4.2 \mathrm{mg} / \mathrm{dl} / \mathrm{min}$ ) [1416]. This high value and improvements in photometric techniques and sampling, leading to more reliable and sensitive measurement, permit us to measure the rate continuously in the short periods. The current study was conducted to measure the secretion rate of triglyceride from rat liver by both methods of fixed-time and continuous monitoring and to compare the results.

\section{Material and methods}

Poloxamer (P-407) was obtained from Sigma (USA) and diethyl ether was purchased from Merck. All other chemicals and solvents were of reagent quality and were obtained from local suppliers.

\section{Animals, diets}

Thirty-five albino (Wistar) male rats were obtained from the animal center at our university and housed in a room with a 12-h light/dark cycle under constant temperature $\left(25^{\circ} \mathrm{C}\right)$ for 15 days. The rats were about 50 days old (weighing 200-220 g) and were fed standard rodent laboratory food and starved overnight $(12 \mathrm{~h})$ before blood sampling. All experimental pro- cedures were performed in accordance with the Guide for the Care and Use of Laboratory Animals (GCULA) and approved by ethics committee of our university.

\section{Poloxamer injection}

All experiments were commenced at 9.00 a.m. Poloxamer was dissolved in isotonic saline as $20 \%$ solution with slight agitation in an ice bath and left standing for a few hours [14]. One milliliter of detergent $(1000 \mathrm{mg} / \mathrm{kg})$ was injected intra-peritoneally (i.p.) and the time adjusted as zero 30 minutes thereafter for all experiments.

\section{Venipuncture for fixed-time and kinetic assays}

After 30 minutes lag time, the blood samples $(200 \mu \mathrm{l})$ were taken from the tail vein at defined times of 0,15 , $30,60,120,180$ and 240 minutes under very light ether anesthesia. Blood taking was not successful at all points of time for all rats.

For the kinetic assay, the blood samples were taken from the inferior vena cava above the kidney at 0,5 , 10,15 minute intervals usually at the time of one hour. We took the blood sample first from the tail vein and then from the inferior vena cava after laparotomy. The absorbance of triglyceride was reduced about 0.010 (less than 5\%) by this shifting in the blood sampling, so multiple blood samples were drawn from the vena cava for simplicity and to improve the agreement of the results. After withdrawing the needle, a cotton ball was pushed gently on the site and held to prevent bleeding. If there was bleeding, the blood that entered the peritoneal cavity could not be collected for the measurement of triglyceride. The remaining poloxamer in the cavity inhibits lipase in the kit for triglyceride measurement, so the assay underestimates the value. The blood serum was separated by 5 minutes centrifugation at $3000 \mathrm{rpm}$ and stored at $4^{\circ} \mathrm{C}$ before analysis or at $-70^{\circ} \mathrm{C}$ for longer preservation.

\section{Measurement of serum lipids}

Triglyceride was measured on fresh serum in duplicate by the enzymatic method of GPO-PAP, shaking in a water bath at $37^{\circ} \mathrm{C}$ for 10 minutes (Pars-Azmon Inc., Tehran).

\section{Statistical analysis}

The results are presented as the means \pm standard deviations of the means (SD) of two inter-assays performed in 5-9 different rats at each point of time. To compare the methods, the values of means and stan- 
dard deviations were compared by using $t$ - and $F$-tests respectively. The percentage coefficient of variation $(\mathrm{CV} \%)$ is calculated as standard deviation divided per mean. Linear regression was used to show the results of measurements at three points of time. Standard deviations for the slopes of the lines of linear regression (SDr) were calculated as follows:

$$
\sqrt{\frac{\sum_{i}^{n}\left(y_{i}-\bar{y}\right)^{2}}{n-2}}
$$

using Excel software, in which $\left(\mathrm{y}_{\mathrm{i}}-\overline{\mathrm{y}}\right)$ is the error in the predicted value (by regression line) and $n-2$ is degrees of freedom.

\section{Results}

\section{Overall time course for changes of serum triglyceride}

The time course for the changes of serum triglyceride following injection of a single dose of P-407 showed three distinct phases (Fig. 1). The basal fasting concentration of triglyceride was $59.6 \pm 9.6 \mathrm{mg} / \mathrm{dl}$ and after a 30 minutes lag period (first phase) rose linearly during 4 hours tested here (second phase). In the third phase, triglyceride accumulation declined slightly and it reached $2668.3 \pm 169.7 \mathrm{mg} / \mathrm{dl}$ after 24 hours. The linear portion of Fig. $1 \mathrm{~A}$ is shown in Fig. $1 \mathrm{~B}$ to em-

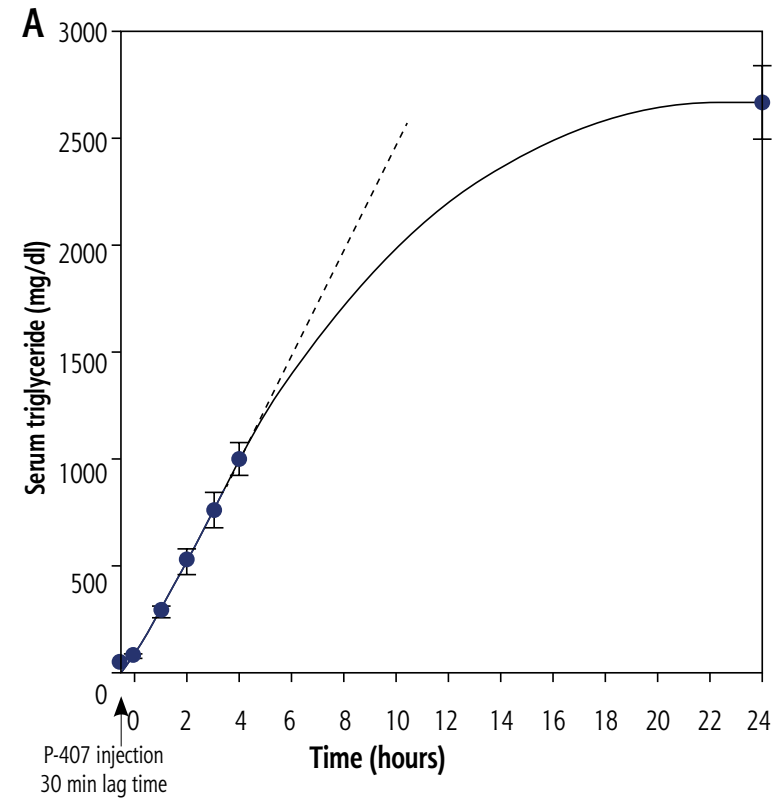

phasize the existence of a lag period of approximately 30 minutes and the linear accumulation of triglyceride up to 4-6 hours. The slope of the line during this phase indicates the mean rate of triglyceride secretion as $234.1 \pm 9.6 \mathrm{mg} / \mathrm{dl}$.h. According to Fig. 1, correct results cannot be obtained if the rate is measured during the lag phase (I) or during phase III.

\section{Fixed-time assay of VLDL-triglyceride secretion rate}

We divided the linear phase into five time protocols: 240, 180, 120, 60 and 30 minutes (Fig. 2). In any protocol, the blood samples were taken at three points of time and the concentration of triglyceride was measured. Protocols A, B and C are more classically used and the blood samples are taken three times up to 240, 180 and 120 minutes respectively [5-8]. In protocols $\mathrm{D}$ and $\mathrm{E}$, the time of sampling was reduced to 60 and 30 minutes. The protocol with the measurements at the first 5, 10 and 15 minutes was not performed because there was a great variation in the lag time between animals. The mean rate of triglyceride secretion was deduced from the equations of the lines as $3.91 \pm 0.15$, $3.83 \pm 0.16,3.76 \pm 0.29,3.57 \pm 0.43$ and $3.13 \pm 0.34 \mathrm{mg} /$ $\mathrm{dl} / \mathrm{min}$ in these protocols respectively. It is observed that, as the time interval is decreased from 240 to 30 minutes, the mean rate of triglyceride secretion tends to decrease slightly but not significantly. P-407 in

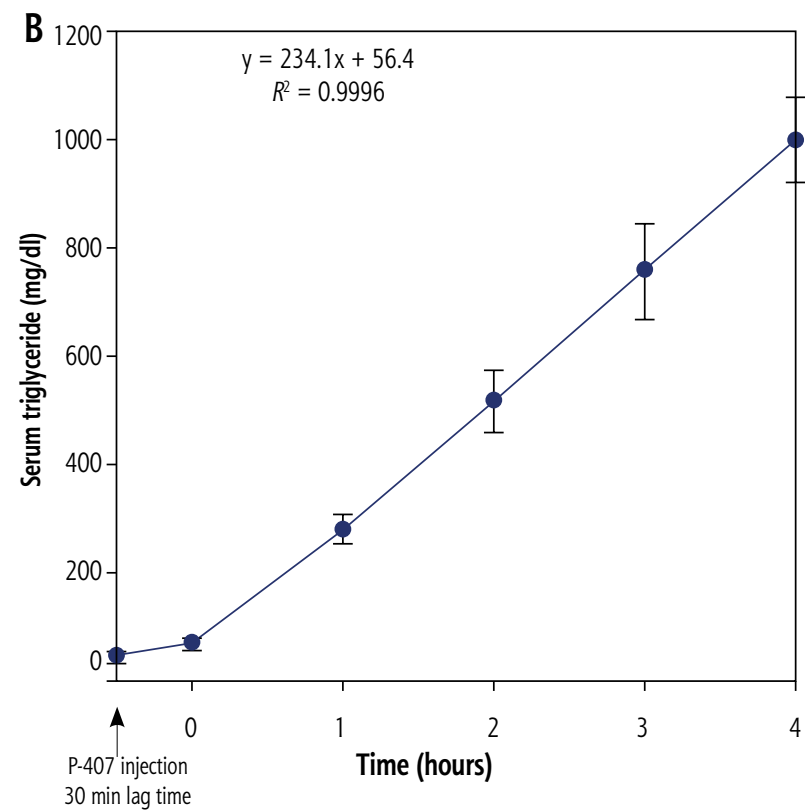

Fig. 1. A) Overall time course for the changes of serum triglyceride following injection of poloxamer. A single dose of $200 \mathrm{mg}$ P-407 was injected by i.p and the zero time adjusted as 30 minutes thereafter. Values are means \pm SD of two inter-assays performed in five up to nine different rats. B) Linear region of the changes for serum triglyceride 

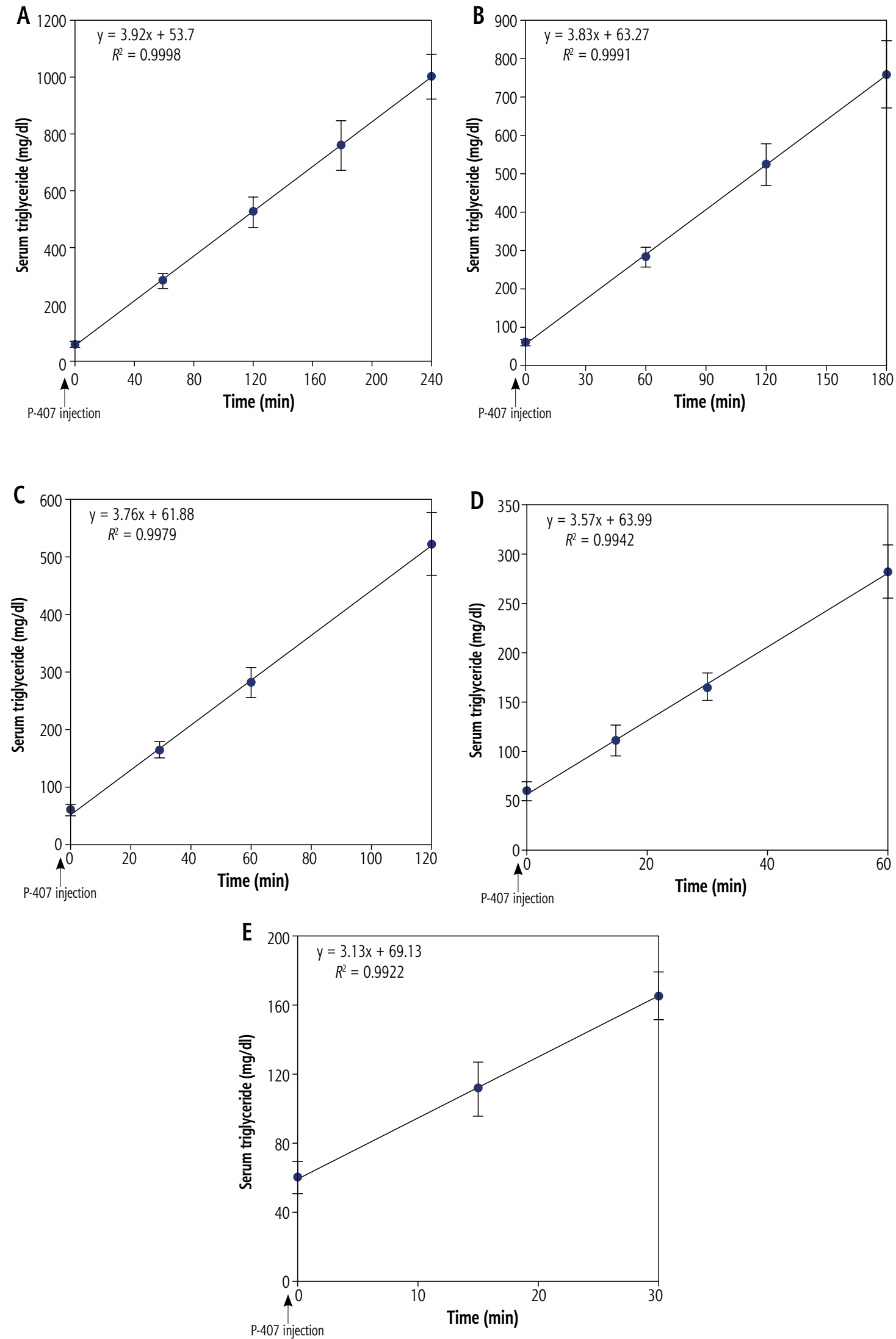

Fig. 2. Fixed-time protocols to measure the mean velocity of triglyceride secretion. A single dose of $200 \mathrm{mg}$ of P-407 was injected i.p. and zero time adjusted as 30 minutes thereafter. Values are means \pm SD of two inter-assays performed in five to nine different rats 
Table 1. Continuous assay of VLDL-triglyceride secretion rate. A single dose of $200 \mathrm{mg}$ of P-407 was injected i.p. and zero time adjusted as 30 minutes thereafter. At the time of 1 hour, the peritoneal cavity was opened and another four samples were drawn from the vena cava at 0,5,10 and 15 minutes. Values are the means of two inter-assays; the results of any experiment in one separate rat are presented in one row

\begin{tabular}{|c|c|c|c|c|c|}
\hline $\begin{array}{l}\text { Basal absorbance } \\
\text { at } 60 \text { minutes }\end{array}$ & $\Delta \mathrm{A}_{1} / 5$ & $\begin{array}{l}\text { Absorba } \\
\Delta A_{2} / 5\end{array}$ & $\Delta \mathrm{A}_{3} / 5$ & $\Delta \mathrm{A} / 15$ & $\begin{array}{c}V_{s} \\
(\mathrm{mg} / \mathrm{dl} / \mathrm{min})\end{array}$ \\
\hline 0.254 & 0.030 & 0.021 & 0.022 & 0.073 & 3.82 \\
\hline 0.302 & 0.030 & 0.018 & 0.027 & 0.074 & 3.92 \\
\hline 0.258 & 0.020 & 0.029 & 0.022 & 0.071 & 3.71 \\
\hline
\end{tabular}

Table 2. Comparison of the results of measurement of triglyceride secretion rate from rat liver by classical fixed-time and kinetic assay methods. In the fixed-time method, the measurement was made at one or three points of time. The values of means and coefficients of variation (CV\%) were compared to the first row (single point at $240 \mathrm{~min}$ ) using $t$ - and F-tests respectively. SDr stands for standard deviation about the regression

\begin{tabular}{|c|c|c|c|c|}
\hline Method & Mean $\pm \mathrm{SD}(\mathrm{mg} / \mathrm{dl} / \mathrm{min})$ & $\mathrm{CV} \%$ & $p$-value (t-test) & $p$-value (F-test) \\
\hline Classical assay at a single-point & Mean $\pm S D$ & & & \\
\hline $240 \min$ & $3.91 \pm 0.45$ & $11.5 \%$ & - & - \\
\hline $180 \min$ & $3.88 \pm 0.49$ & $12.5 \%$ & 0.927 & 0.522 \\
\hline $120 \mathrm{~min}$ & $3.82 \pm 0.48$ & $12.7 \%$ & 0.872 & 0.857 \\
\hline $60 \mathrm{~min}$ & $3.71 \pm 0.43$ & $11.8 \%$ & 0.608 & 0.717 \\
\hline $30 \mathrm{~min}$ & $3.53 \pm 0.47$ & $13.2 \%$ & 0.307 & 0.791 \\
\hline Classical assay at multiple points & Mean \pm SDr & & & \\
\hline $240,180,120,60 \mathrm{~min}$ & $3.91 \pm 0.15$ & $4.0 \%$ & 0.848 & 0.019 \\
\hline $180,120,60 \mathrm{~min}$ & $3.83 \pm 0.16$ & $4.2 \%$ & 0.806 & 0.058 \\
\hline $120,60,30 \mathrm{~min}$ & $3.76 \pm 0.29$ & $7.6 \%$ & 0.547 & 0.091 \\
\hline $60,30,15 \mathrm{~min}$ & $3.57 \pm 0.43$ & $12.4 \%$ & 0.335 & 0.175 \\
\hline $30,15 \mathrm{~min}$ & $3.13 \pm 0.34$ & $10.9 \%$ & 0.155 & 0.171 \\
\hline Kinetic assay & Mean $\pm S D r$ & & & \\
\hline $5,10,15 \min$ & $3.82 \pm 0.11$ & $2.7 \%$ & 0.831 & 0.064 \\
\hline
\end{tabular}

the peritoneal cavity is absorbed gradually and enters the general blood stream, a process that lasts different lengths of time in the rats. Thus, the inhibition of LPL is not complete at the initial period and the measurement of triglyceride secretion is underestimated. For this reason, as long as the time interval is closer to the lag time and compromises it more, the assay of secretion rate will be more underestimated.

\section{Continuous monitoring of VLDL-triglyceride secretion rate}

In the kinetic assay of plasma enzymes, the progress of the reaction is monitored continuously, usually at the initial three consecutive one-minute intervals. The changes in the absorbance of our samples were as small as 0.005 per minute, so we chose three successive five-minute intervals for blood sampling. The change in the absorbance in the three next five-minute periods $(\Delta \mathrm{A} / \Delta \mathrm{t})$ is shown in Table 1 for three rats. In the last column, the secretion rate is presented for different rats as about $3.82 \pm 0.11 \mathrm{mg} /$ $\mathrm{dl} / \mathrm{min}$. This value is very similar to the instantaneous velocity and is comparable to the mean velocity obtained by the classical fixed-time assay.

\section{Comparison of fixed-time and kinetic assays}

The rate of triglyceride secretion from rat liver was measured by classical fixed-time and kinetic methods, and the results are presented in Table 2. In the fixedtime method, the assay was done at a single or multiple points of time. The values of means and CV\% were compared to the values obtained at a single point of 240 minutes (first row) using $t$ - and $F$-tests respectively. SDr stands for standard deviation about the regression.

All fixed-time assays performed at a single point had a high CV\% of about $10 \%$. In the fixed-time assay, if the measurement was done at three times the CV\% will decrease to the acceptable level of 5\%, especially for the protocols of 240, 180 and 120 minutes. The decrease in time of the protocols from 240, to 180, 120, 60 and 30 minutes tends to decrease the means and to increase 
the CV\% slightly. The decrease in the means is not due to analytical error, but is correlated with interference of the lag time and incomplete inhibition of LPL by P-407. The increase in CV\% is analytically attributed to the decrease in the absorbance of the samples with lower levels of triglyceride and the variations between animals.

\section{Discussion}

The results of the current study show that: 1 . If the rate of triglyceride secretion is measured at a single point of fixed time (e.g. at 2 hours) the CV\% of the assay will be high. But multiple assays at different times reduce the CV\% to about 5\%. 2. In the fixed-time method, the time of the assay can be shortened from 240 to 180, 120, 60 and 30 minutes. The reduction of the time was accompanied by a slight decrease of the mean and increase in standard deviation of the method. 3. The rate can be monitored continuously at three successive five-minute intervals at any part of the linear region. This is the first experiment that has applied continuous monitoring to measure the instantaneous rate of triglyceride secretion from rat liver. The rate of triglyceride secretion in starved male rats obtained here using both fixed-time and continuous assays was $3.82 \pm 0.11 \mathrm{mg} / \mathrm{dl} / \mathrm{min}$, which is comparable to the average value obtained from different references [14-16]. The two methods have different advantages and limitations. The results of the continuous monitoring method are more quickly attainable and closer to instantaneous velocity but are more sensitive to analytical errors.

\section{Instantaneous versus mean secretion rate}

Very-low-density lipoprotein is assembled by apolipoprotein-B and the lipid portion, mainly triglyceride, cholesterol and phospholipids [17]. The liver secretes VLDL continuously and the secretion is under acute and chronic regulation. Some factors regulate the secretion acutely, i.e. in seconds and minutes [18-20], while others have long actions on VLDL secretion, i.e. over hours and days $[21,22]$. Thus, sometimes it is necessary to measure the secretion rate in a short time. In the fixed-time assay, the mean rate of secretion is measured along the time, usually during three hours. The value obtained by the fixed-time method contains both the first interval, when the P-407 has not entered the blood stream completely, and the last stage, when the inhibitor has entered the liver and directly affects the synthesis and secretion of VLDL $[24,25]$. However, in the continuous or kinetic assay it is possible to measure the instantaneous velocity at any point of time. The instantaneous velocity is defined as the limit of $\Delta \mathrm{C}$ (or $\Delta \mathrm{A}) / \Delta \mathrm{t}$ when $\Delta \mathrm{t}$ goes to zero, where
$\mathrm{C}$ and $\mathrm{A}$ stand for concentration and absorbance respectively. In the kinetic assay of the enzyme activity, the change in absorbance is high enough to measure during the initial three successive one-minute periods. But the change in the absorbance of the samples in this study was low, so it is hard to see significant and reproducible change in a shorter period. In the kit that we used to measure triglyceride the ratio of standard concentration to absorbance was $200(\mathrm{mg} / \mathrm{dl}) / 0.250$, but some kits have higher sensitivity. So it is possible to monitor the rate of secretion at a shorter time such as three successive 2.5-minute periods, if such kits are used. In general, it is preferred to shorten the time of the assay. However, analytically it causes the standard deviation and CV\% of the method to increase. Such changes can be avoided by measuring the rate at multiple points of time (Table 2). By using multiple assays, $\mathrm{SD}$ is substituted by $\mathrm{SD}$ of regression (SDr) and the results will be improved.

\section{Initial velocity is attainable just following i.v. injection}

Tyloxapol, another LPL inhibitor, is usually injected intravenously (i.v.) and after 5 minutes lag time causes complete inhibition of triglyceride clearance [8]. Therefore, it is possible to measure the initial velocity of triglyceride secretion in the first minutes following i.v. injection of tyloxapol. However, poloxamer is injected i.p. and there is a variable lag time of about 30 minutes to enter the blood stream and inhibit LPL completely. This uncertainty in the duration of the lag time can be seen in the initial level of triglyceride after i.p. injection in different references $[26,27]$. So, initial velocity cannot be measured correctly if P-407 is administered i.p.

\section{Nutrition and anesthesia are important interfering factors}

There is a standard dried food for animals, but usually it is deficient in fresh vitamins, minerals, carbohydrates, lipids and proteins. So we observed that in the rats with standard chow the level of glycogen in the liver was near to zero even in a fed state and the plasma triglyceride did not increase after the injection of LPL inhibitor [18, 19]. Malnutrition impairs triglyceride secretion by up to $90 \%$, especially after one hour following the injection of LPL inhibitor (results not shown) [4]. Thus the rats must have required nutrition during the week preceding the experiment to show normal metabolism such as VLDL secretion.

Anesthesia with ether is the second important factor that may influence the rate of triglyceride secretion. As reported previously, repeat exposure to ether can 
reduce the rate of secretion by up to $35 \%$ [4]. This effect of ether is only significant when it is repeated at a short interval of less than 30 minutes but not more than 60 minutes. To prevent such an effect, we used very light anesthesia, the blood was taken rapidly and the rats were used only at one point of time.

\section{Conclusions}

The rate of triglyceride secretion can be measured by both fixed-time and continuous assays. The results of the two methods are more corresponded as the mean and instantaneous velocity respectively. The rate of triglyceride secretion obtained by both methods was about $3.82 \pm 0.11 \mathrm{mg} / \mathrm{dl} / \mathrm{min}$.

\section{Acknowledgements}

This work was supported by a grant from the University of Mazandaran for Medical Research.

\section{Disclosure}

The authors declare no conflict of interest.

\section{References}

1. Rasouli M, Kiasari AM. Interactions of lipoprotein(a) with diabetes mellitus, apolipoprotein $\mathrm{B}$ and cholesterol enhance the prognostic values for coronary artery disease. Clin Chem Lab Med 2008; 46: 667-673.

2. Mead JR, Irvine SA, Ramji DP. Lipoprotein lipase: structure, function, regulation, and role in disease. J Mol Med (Berl) 2002; 80: 753-769.

3. Rasouli M, Haghighi B, Suzangar M. Diurnal variations in hepatic and plasma lipids and the activities of hepatic phosphatidate phosphohydrolase and heart lipoprotein lipase. Iran J Med Sci 1991; 16: 46-53.

4. Otway S, Robinson DS. The use of a non-ionic detergent (Triton WR 1339) to determine rates of triglyceride entry into the circulation of the rat under different physiological conditions. J Physiol 1967; 190: 321-332.

5. Palmer JF, Cooper C, Shipley RA. Rate of release of hepatic triacylglycerol into serum in the starved rat. Biochem J 1978; 172: 219-226.

6. Sato K, Akiba Y, Kimura S, Horiguchi M. Species differences between chicks and rats in inhibition of lipoprotein hydrolysis by Triton WR1339. Comp Biochem Physiol 1995; 112C: 315-319.

7. Siddiqi SA, Clay R, Siddiqi S. Vitamin E reduces hepatic VLDL secretion by disrupting its ER-to-Golgi transport. FASEB J xxx; 33: 490.13.

8. Korolenko TA, Johnston TP, Tuzikov FV, et al. Early-stage atherosclerosis in poloxamer 407-induced hyperlipidemic mice: pathological features and changes in the lipid composition of serum lipoprotein fractions and subfractions. Lipids Health Dis 2016; 5: 16.

9. Stafford JM, Yu F, Printz R, et al. Central nervous system neuropeptide Y signaling modulates VLDL triglyceride secretion. Diabetes 2008; 57: 1482-1490.

10. Kwak YS, Kyung JS, Kim JS, et al. Anti-hyperlipidemic effects of red ginseng acidic polysaccharide from Korean red ginseng. Biol Pharm Bull 2010; 33: 468-472.
11. Takahashi Y, Inaba N, Kuwahara S, Kuki W. Effects of gamma-terpinene on lipid concentrations in serum using Triton WR1339-treated rats. Biosci Biotechnol Biochem 2003; 67: 2448-2450.

12. Dhalla AK, Santikul M, Smith M, et al. Antilipolytic activity of a novel partial A1 adenosine receptor agonist devoid of cardiovascular effects: comparison with nicotinic acid. J Pharmacol Exp Therap 2007; 321: 327-333.

13. Rasouli M. Principles of Medical Biochemistry. 1st ed. Roojin Mehr 2016; 777-786

14. Milar JS, Cromley DA, McCoy MG, et al. Determining hepatic triglyceride production in mice: comparison of poloxamer 407 with Triton WR1339. J Lipid Res 2005; 46: 2023-2028.

15. Rasouli M, Tahmouri H, Mosavi-Mehr M. The long term kinetic of plasma lipids and lipoproteins in tyloxapol injected rats. J Clin Diagn Res 2016; 10: BF01-5.

16. Johnston TP. The P-407 induced murine model of dose controlled hyperlipidemia and atherosclerosis. J Cardiovasc Pharmacol 2004; 43: 595-606.

17. Rasouli M, Trischuk T, Lehner R. Calmodulin antagonist W-7 inhibits de novo synthesis of cholesterol and suppresses secretion of de novo synthesized and preformed lipids from cultured hepatocytes. Biochem Biophysic Acta 2004; 1682: 92-101.

18. Rasouli M, Mosavi-Mehr M, Tahmouri H. Liver denervation increases the levels of serum triglyceride and cholesterol via increases in the rate of VLDL secretion. Clin Res Hepatol Gastroenterol 2012; 36: 60-65.

19. Nikfar A, Rasouli M. Hypolipemic effects of histamine is due to inhibition of VLDL secretion from the liver: involvement of both $\mathrm{H} 1$ and H2-receptors. Arch Physiol Biochem 2020. https://doi.org/10.1080/ 13813455.2020.1782436.

20. Fisher E, Lake E, McLeod RS. Apolipoprotein B100 quality control and the regulation of hepatic very low density lipoprotein secretion. J Biomed Res 2014; 28: 178-193.

21. Wang Y, Lin Q, Zheng P, et al. Effects of eicosapentaenoic acid and docosahexaenoic acid on chylomicron and VLDL synthesis and secretion in Caco-2 cells. Biomed Res Int 2014; 2014: 684325.

22. Han S, Liang C, Westerterp M, et al. Hepatic insulin signaling regulates VLDL secretion and atherogenesis in mice. J Clin Invest 2009; 119: 1029-1041.

23. Schonewille M, Brufau G, Shiri-Sverdlov R, et al. Serum TG-lowering properties of plant sterols and stanols are associated with decreased hepatic VLDL secretion. J Lipid Res 2014; 55: 2554-2561.

24. Soler-Argilaga C, Russel RL, Heimberg M. Effects of Triton WR1339 on lecithin- cholesterol acyltransferase. Arch Biochem Biophys 1977; 178: 135-139.

25. Trout JJ, Viles JM. Cellular changes associated with Triton WR1339 accumulation in rat hepatocytes, III cellular clearance. Exp Mol Pathol 1981; 34: 183-190.

26. Brenachot X, Gautier T, Nédélec E, et al. Brain control of plasma cholesterol involves polysialic acid molecules in the hypothalamus. Front Neurosci 2017; 11: 245

27. Rasouli M, Nesarhosseini V, Kiasari AM, et al. The multiplicative interactions of leukocyte counts with some other risk factors enhance the prognostic value for coronary artery disease. Cardiol J 2011; 18: 246-253. 